\title{
SCIENTIFIC REP

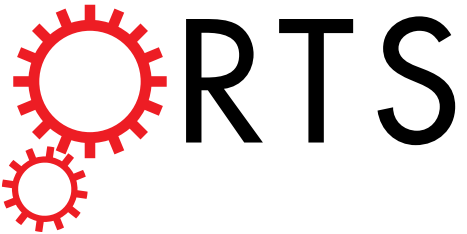 \\ OPEN \\ Tranexamic acid evokes pain by modulating neuronal excitability in the spinal dorsal horn
}

Received: 28 June 2015

Accepted: 27 July 2015

Published: 21 August 2015

\author{
Nobuko Ohashi ${ }^{1}$, Mika Sasaki $^{1}$, Masayuki Ohashi ${ }^{2}$, Yoshinori Kamiya $^{1}$, Hiroshi Baba ${ }^{1}$ \& \\ Tatsuro Kohno ${ }^{1}$
}

Tranexamic acid (TXA) is an antifibrinolytic agent widely used to reduce blood loss during surgery. However, a serious adverse effect of TXA is seizure due to inhibition of $\gamma$-aminobutyric acid (GABA) and glycine receptors in cortical neurons. These receptors are also present in the spinal cord, and antagonism of these receptors in spinal dorsal horn neurons produces pain-related phenomena, such as allodynia and hyperalgesia, in experimental animals. Moreover, some patients who are injected intrathecally with TXA develop severe back pain. However, the effect of TXA on spinal dorsal horn neurons remain poorly understood. Here, we investigated the effects of TXA by using behavioral measures in rats and found that TXA produces behaviors indicative of spontaneous pain and mechanical allodynia. We then performed whole-cell patch-clamp experiments that showed that TXA inhibits $\mathrm{GABA}_{\mathrm{A}}$ and glycine receptors in spinal dorsal horn neurons. Finally, we also showed that TXA facilitates activation of the extracellular signal-regulated kinase in the spinal cord. These results indicated that TXA produces pain by inhibiting $\mathrm{GABA}_{\mathrm{A}}$ and glycine receptors in the spinal dorsal horn.

Tranexamic acid (TXA) is a synthetic lysine derivative that acts as an antifibrinolytic drug by inhibiting plasminogen activation and preventing fibrin degradation ${ }^{1-5}$. TXA is therefore commonly used to reduce perioperative blood loss, particularly during cardiac and orthopedic surger ${ }^{6-10}$. However, several clinical studies reported that patients treated with TXA had a higher incidence of seizure after cardiopulmonary bypass $^{11-13}$. TXA-associated seizure presumably results from inhibition of $\gamma$-aminobutyric acid (GABA) and glycine receptors in the brain, as the drug has been shown to inhibit these receptors in embryonic kidney cells and primary cortical neuron cultures ${ }^{14-16}$.

GABA and glycine are co-released by spinal dorsal horn neurons and are important in regulating sensory processing ${ }^{17-20}$. In addition, GABA and glycine receptors are abundant in the spinal cord, and antagonism of these receptors produces pain phenomena, such as allodynia and hyperalgesia ${ }^{21-24}$. Assuming that TXA acts as a $\mathrm{GABA}_{\mathrm{A}}$ and glycine receptor antagonist in the spinal dorsal horn as well as in the cortex, we hypothesized that TXA evokes pain. Indeed, several clinical studies have reported that patients to whom TXA was accidentally injected intrathecally immediately complained of severe back pain ${ }^{25-29}$. Moreover, it has been reported that patients treated with TXA required higher doses of analgesics ${ }^{30,31}$. In addition, patients with menorrhagia who received TXA experienced a higher incidence of headache, abdominal pain, and back pain than did placebo-treated patients ${ }^{32}$. Thus, it seems possible that TXA impairs neuronal inhibition via blockade of $\mathrm{GABA}_{\mathrm{A}}$ and glycine receptors and thereby produces pain at the spinal cord level. However, no previous studies have directly evaluated the effects of TXA on synaptic transmission in spinal dorsal horn neurons. In the present study, we therefore investigated

${ }^{1}$ Division of Anesthesiology, Niigata University Graduate School of Medical and Dental Sciences, 1-757 Asahimachi Dori, Chuo-Ku, Niigata City, 951-8510 Japan. ${ }^{2}$ Division of Orthopedic Surgery, Department of Regenerative and Transplant Medicine, Niigata University Graduate School of Medical and Dental Sciences, 1-757 Asahimachi Dori, Chuo-Ku, Niigata City, 951-8510 Japan. Correspondence and requests for materials should be addressed to T.K. (email: kohno-t@umin.net) 


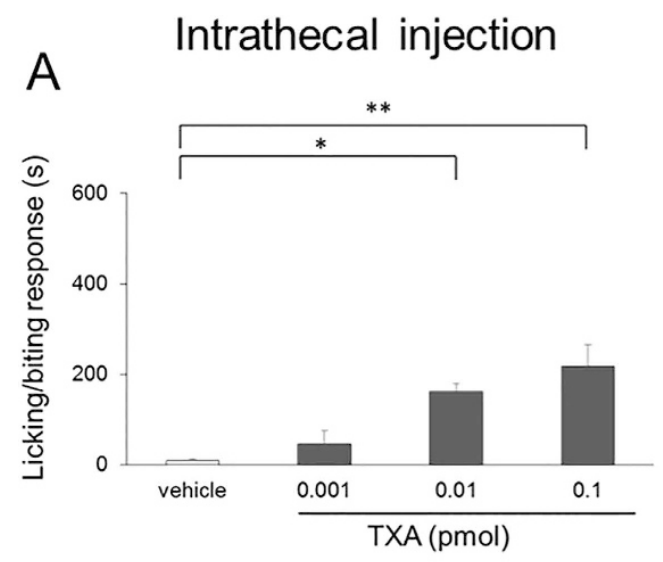

Intraperitoneal injection
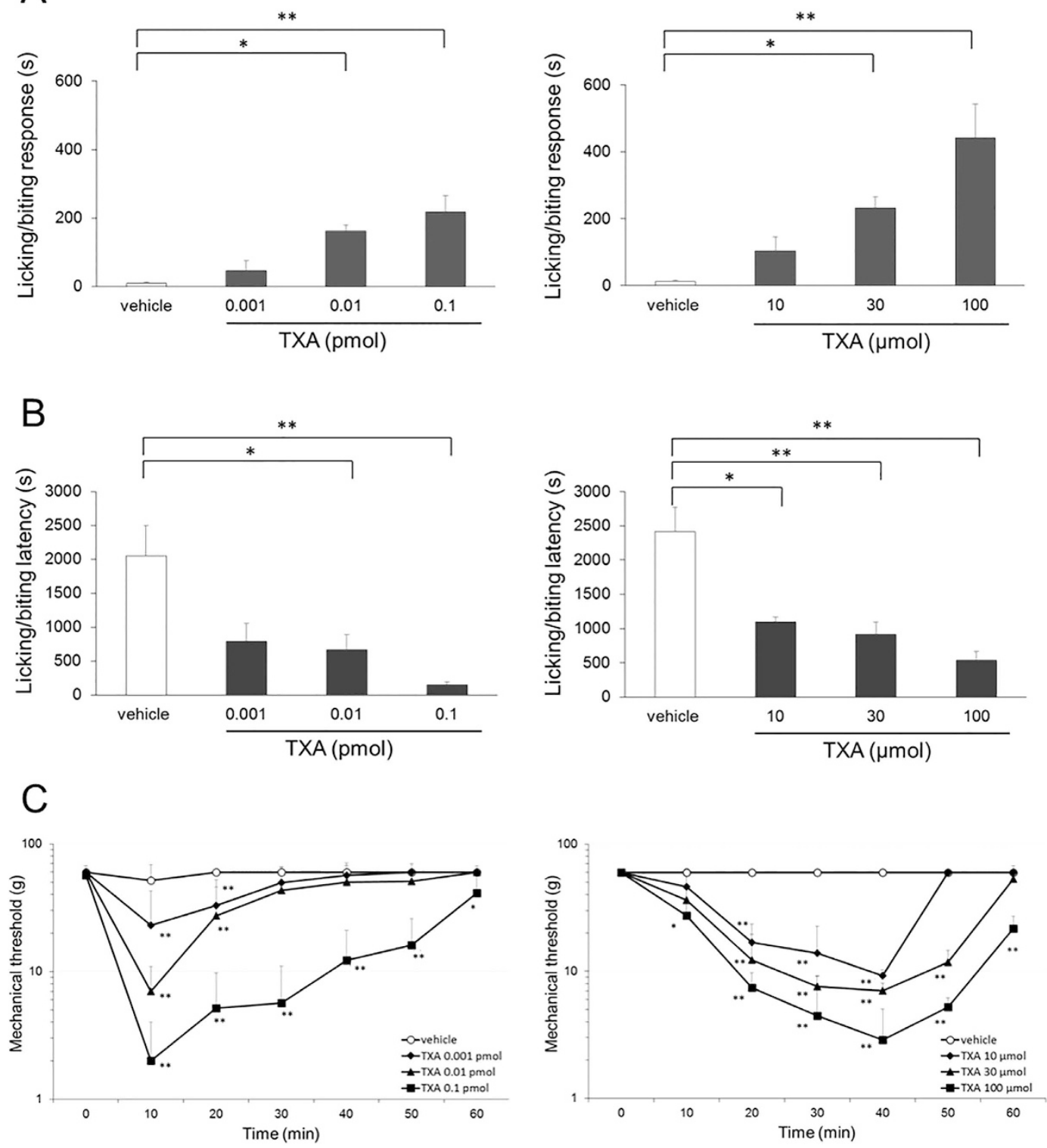

Figure 1. Assessment of behavioral response to intrathecal and intraperitoneal injection of tranexamic acid (TXA). (A) Total time devoted to licking/biting responses during a 60-min observation period is increased in a concentration-dependent manner by intrathecal or intraperitoneal injection of TXA. (B) The latency to the start of the behavior is shortened in a concentration-dependent manner by intrathecal or intraperitoneal injection of TXA. (C) Mechanical thresholds for paw withdrawal in response to von Frey stimulation are significantly reduced in a concentration-dependent manner by intrathecal or intraperitoneal injection of TXA. Concentrations of intrathecal or intraperitoneal injected TXA range from 0.001 to $0.1 \mathrm{pmol}$ and from 10 to $100 \mu \mathrm{mol}$, respectively. The data are given as mean $\pm \mathrm{SD}$. In each dose group, $n=5$; ${ }^{\star} P<0.05,{ }^{*} P<0.01$ by one or two-way ANOVA.

whether clinical levels of TXA regulate synaptic transmission in the spinal cord, using behavioral measures, whole-cell patch-clamp techniques, and immunohistochemical analyses.

\section{Results}

TXA administration evokes spontaneous pain-like behavior and mechanical allodynia. To examine whether TXA evokes pain responses, we investigated the actions of TXA using behavioral measures, such as licking/biting, in rats. Total time devoted to licking/biting behaviors during the 60-min period following intrathecal or intraperitoneal injection of TXA increased in a concentration-dependent manner at doses from 0.001 to $0.1 \mathrm{pmol}$ or from 10 to $100 \mu \mathrm{mol}$, respectively (each dose group: $n=5$, $P<0.05$ by one-way ANOVA, Fig. 1A). Similarly, the latency between TXA injection and the onset 

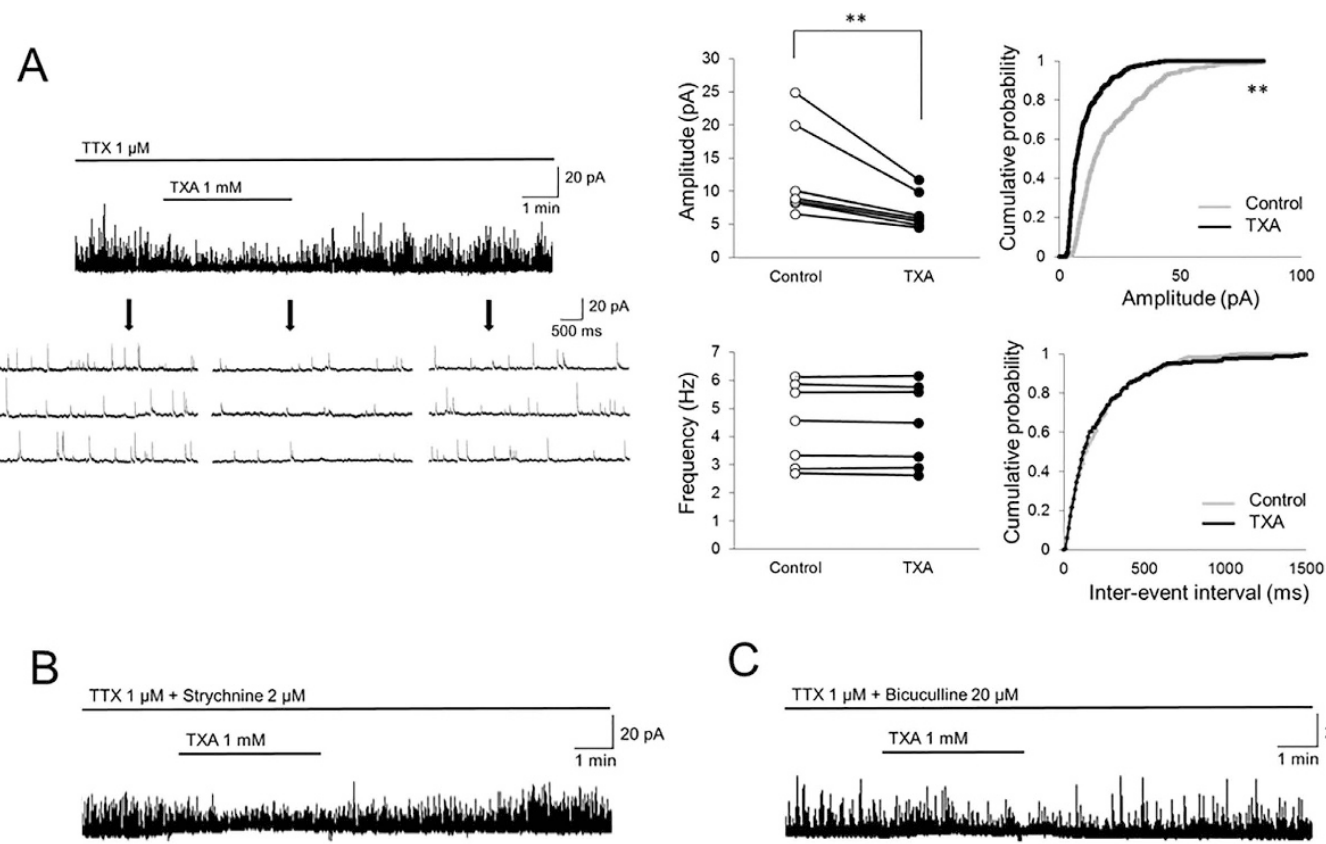

C
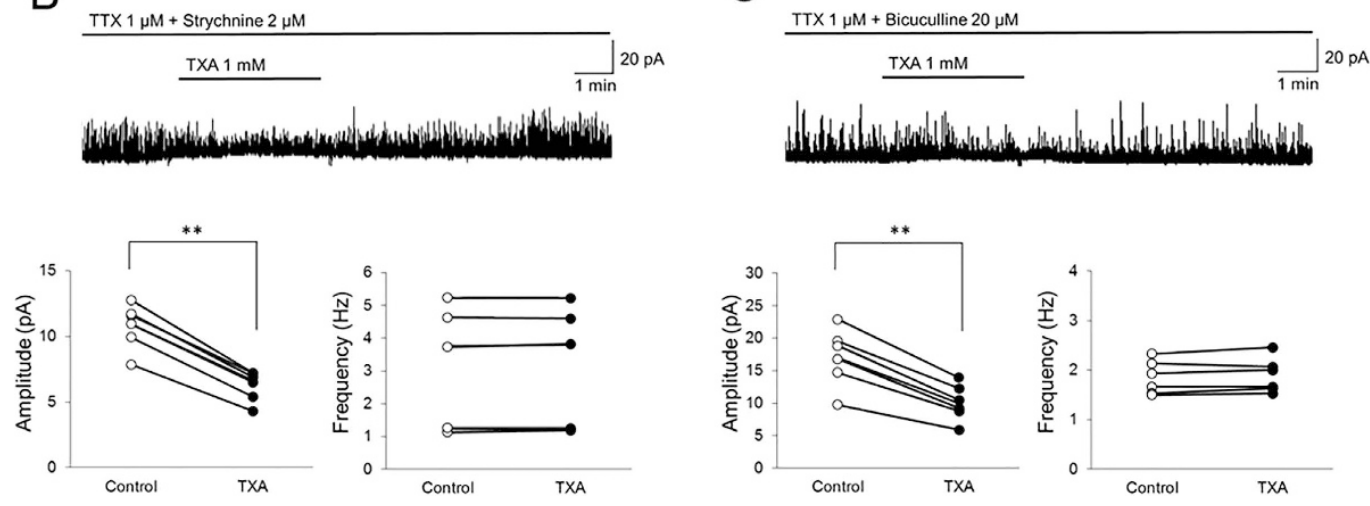

Figure 2. Tranexamic acid (TXA) decreases the amplitude of GABAergic and glycinergic mIPSCs without changes in frequency. (A) TXA ( $1 \mathrm{mM}, 2 \mathrm{~min})$ significantly decreases the amplitude of miniature inhibitory postsynaptic currents (mIPSCs) and shifts the cumulative distribution of the amplitudes to the left. In contrast, TXA has no effect on the mIPSC frequency or cumulative distribution of the inter-event intervals $(n=7)$. Downward arrows indicate outtakes of the top trace shown on an expanded timescale. Heavy horizontal bars show periods of drug application. (B) In the presence of strychnine $(2 \mu \mathrm{M})$, a glycine receptor antagonist, TXA ( $1 \mathrm{mM}, 2 \mathrm{~min})$ significantly decreases GABAergic mIPSC amplitude. However, TXA has no effect on GABAergic mIPSC frequency $(n=7)$. (C) In the presence of bicuculline $(20 \mu \mathrm{M})$, a $\mathrm{GABA}_{\mathrm{A}}$ receptor antagonist, TXA $(1 \mathrm{mM}, 2 \mathrm{~min})$ significantly decreases the amplitude of glycinergic mIPSCs. However, TXA has no effect on the frequency of glycinergic mIPSCs $(n=7)$. Holding potential $=0 \mathrm{mV}$ for all recordings. ${ }^{* *} P<0.01$ by paired $t$-test.

of licking/biting behaviors shortened in a concentration-dependent manner (each dose group: $n=5$, $P<0.05$ by one-way ANOVA, Fig. 1B).

The mechanical threshold for paw withdrawal during von Frey stimulation, which measures resistance to evoked pain, was significantly reduced by intrathecal or intraperitoneal injection of TXA in a concentration-dependent manner (each dose group; $n=5, P<0.05$ by two-way ANOVA, Fig. 1C). After intrathecal TXA injection, the sensitized response peaked at $10 \mathrm{~min}$ and then declined to baseline within $60 \mathrm{~min}$. After intraperitoneal injection, the threshold decreased gradually to a peak at $40 \mathrm{~min}$ and lasted for more than $60 \mathrm{~min}$. These results suggested that TXA produces behaviors indicative of spontaneous pain and mechanical allodynia following either intrathecal or intraperitoneal administration.

TXA decreases the amplitude of miniature IPSCs (mIPSCs) without changing their frequency. We next investigated the mechanism of TXA action on SG neurons using the whole-cell patch-clamp technique. As it has been reported that TXA inhibits GABA and glycine receptors in the brain $^{14-16}$, we examined the effect of TXA on inhibitory synaptic transmission pre- and/or postsynaptically. mIPSCs were isolated by adding TTX $(1 \mu \mathrm{M})$ to the perfusate. In the presence of TXA ( $1 \mathrm{mM}$, $2 \mathrm{~min})$, mean mIPSC amplitude decreased from $12.4 \pm 7.1$ to $7.0 \pm 2.8 \mathrm{pA}(59.9 \pm 8.5 \%$ of control, $n=7$, $P<0.01$; Fig. 2A). Conversely, mean mIPSC frequency was unaffected by TXA (control, $4.4 \pm 1.5$; TXA, $4.4 \pm 1.4 \mathrm{~Hz}, 99.4 \pm 1.4 \%$ of control; $n=7, P=0.98$ ). Figure 2A (right panel) shows the effects of TXA on the cumulative distribution of the amplitudes and inter-event intervals of the mIPSCs. When 
A
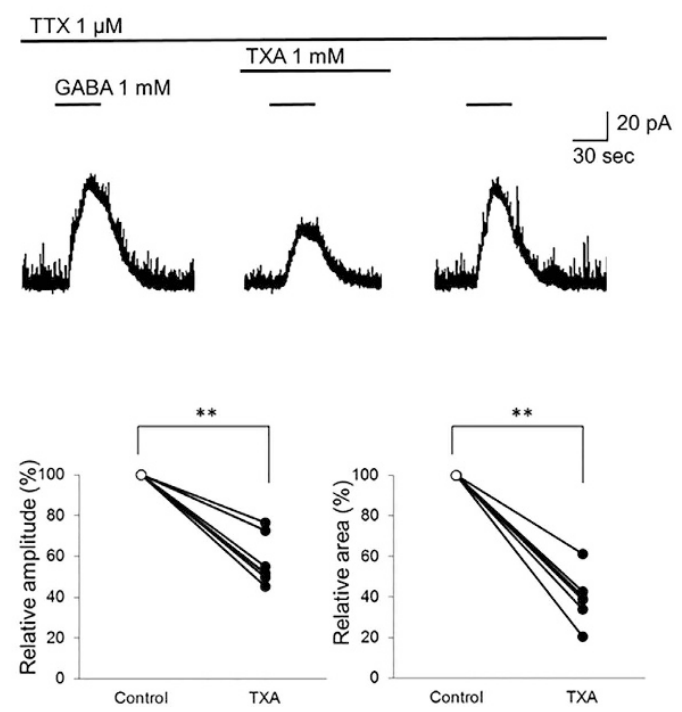

B
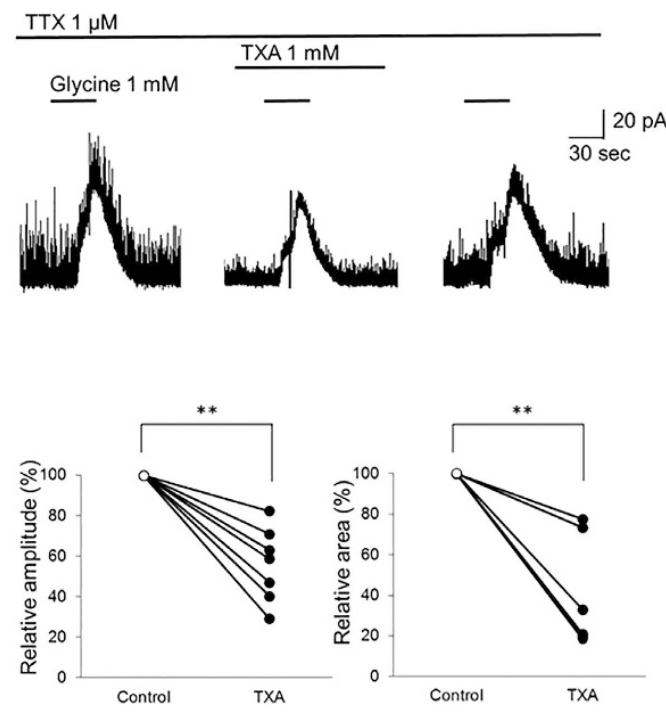

Figure 3. Tranexamic acid (TXA) inhibits the amplitude and decreases the integrated area of currents induced by exogenous GABA or glycine. (A) TXA ( $1 \mathrm{mM}, 2 \mathrm{~min})$ significantly decreases the amplitude and integrated area of the current elicited by exogenous application of GABA ( $1 \mathrm{mM}, 30 \mathrm{~s} ; n=7)$. (B) TXA $(1 \mathrm{mM}, 2 \mathrm{~min})$ significantly decreases the amplitude and integrated area of the current elicited by exogenous application of glycine $(1 \mathrm{mM}, 30 \mathrm{~s} ; n=7)$. Holding potential $=0 \mathrm{mV}$ for all recordings. ${ }^{*} P<0.01$ by paired $t$-test.

compared to the control using the Kolmogorov-Smirnov test, superfusion with TXA increased the proportion of mIPSCs with significantly smaller amplitudes. However, TXA had no effect on the cumulative inter-event interval distribution of the MIPSCs over the recording period. These findings indicate that the TXA-induced decrease in inhibitory activity is postsynaptic in origin.

TXA decreases the amplitude both of GABAergic and glycinergic mIPSCs without changing their frequency. To determine whether TXA acts on GABA or glycine receptors, we investigated the effects of TXA on GABAergic and glycinergic mIPSCs. GABAergic mIPSCs were isolated by adding TTX $(1 \mu \mathrm{M})$ and the glycine receptor antagonist strychnine $(2 \mu \mathrm{M})$ to the perfusate. In the presence of TXA, the mean GABAergic mIPSC amplitude decreased from $10.8 \pm 1.6$ to $6.3 \pm 1.1 \mathrm{pA}(58.2 \pm 2.9 \%$ of control, $n=7, P<0.01$; Fig. 2B). Conversely, mean mIPSC frequency was unaffected by TXA (control, $3.0 \pm 1.8$; TXA, $3.0 \pm 1.7 \mathrm{~Hz}, 101.2 \pm 2.3 \%$ of control; $n=7, P=0.98)$. Similarly, glycinergic mIPSCs were isolated by adding TTX and the $\mathrm{GABA}_{\mathrm{A}}$ receptor antagonist bicuculline $(20 \mu \mathrm{M})$ to the perfusate. In the presence of TXA, mean glycinergic mIPSC amplitude decreased from $17.1 \pm 4.1$ to $10.1 \pm 2.6 \mathrm{pA}$ (59.3 $\pm 2.8 \%$ of control, $n=7, P<0.01$; Fig. 2C). Conversely, mean mIPSC frequency was unaffected by TXA (control, $1.8 \pm 0.3$; TXA, $1.9 \pm 0.3 \mathrm{~Hz}, 102.1 \pm 3.2 \%$ of control; $n=7, P=0.83$ ). These results suggest that TXA inhibits postsynaptic $\mathrm{GABA}_{\mathrm{A}}$ and glycine receptors located on SG neurons.

TXA decreases the amplitude and integrated area of the current elicited by exogenous application of GABA or glycine. Next, we investigated the effects of TXA on the current induced by exogenously administered GABA or glycine $(1 \mathrm{mM}, 30 \mathrm{~s})$ in SG neurons, in the presence of TTX to isolate postsynaptic actions. In the presence of TXA, the mean amplitude of the elicited GABA current decreased to $57.4 \pm 12.2 \%$ of control, and the integrated area decreased to $40.0 \pm 12.1 \%$ of control $(n=7$, $P<0.01$; Fig. 3A).

Similarly, the mean amplitude of the elicited glycine currents decreased to $55.8 \pm 13.8 \%$ of control, and the integrated area decreased to $37.5 \pm 14.6 \%$ of control $(n=7, P<0.01$; Fig. $3 \mathrm{~B})$, in the presence of TXA. These results reinforce the notion that TXA acts as an antagonist at postsynaptic $\mathrm{GABA}_{\mathrm{A}}$ and glycine receptors.

Given that TXA decreases inhibition in SG neurons, it may also increase the potential for neuronal excitation. We therefore investigated action potential discharge activity in current-clamp mode. TXA significantly increased the number of action potentials from $6.9 \pm 2.6$ to $12.0 \pm 4.8(\mathrm{n}=7, P<0.05$ by paired $t$-test) when a depolarizing current was injected into the recorded neurons (Fig. 4A,B).

TXA increases the frequency of spontaneous EPSCs (sEPSCs), but not of miniature EPSCs (mEPSCs), without changing their amplitude. $\mathrm{GABA}_{\mathrm{A}}$ and glycine receptor antagonists affect 
Control

TXA $1 \mathrm{mM}$
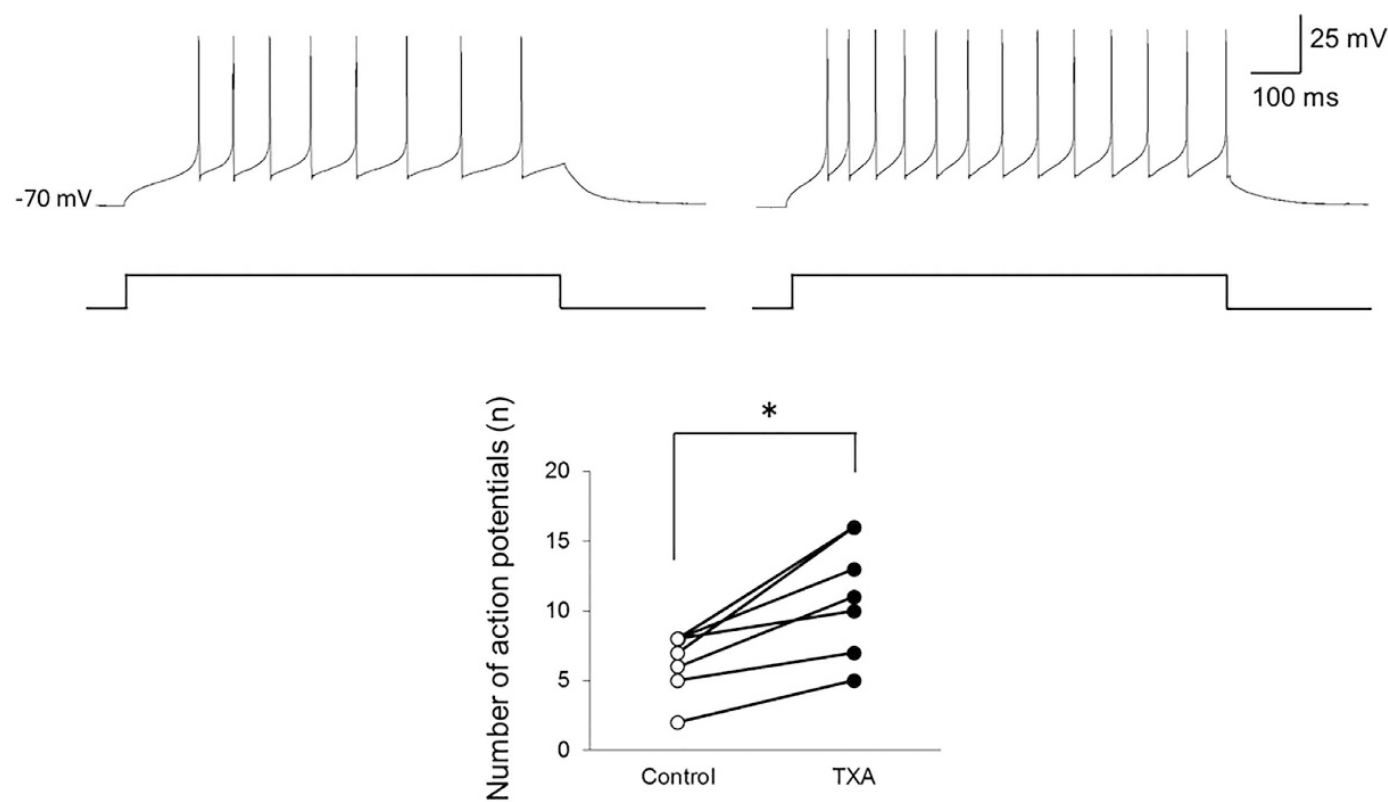

Figure 4. Tranexamic acid (TXA) increases the number of action potentials in dorsal horn neurons. TXA (1 mM) significantly increases the number of action potentials induced by current injection $(100 \mathrm{pA}$, $1000 \mathrm{~ms})$ in all recorded neurons $(n=7) .{ }^{\star} P<0.05$ by paired $t$-test.

excitatory glutamatergic transmission ${ }^{33}$. Therefore, in the next set of experiments, we tested the effects of TXA on sEPSCs and mEPSCs, which represent glutamatergic transmission. In the presence of TXA, the mean sEPSC amplitude was not affected (control, $10.0 \pm 4.7$; TXA, $9.9 \pm 4.3 \mathrm{pA}, 100.6 \pm 7.0 \%$ of control; $n=7, P=0.97$; Fig. 5A). However, the mean sEPSC frequency in the presence of TXA significantly increased from $7.3 \pm 4.2$ to $10.2 \pm 5.1 \mathrm{~Hz}(144.0 \pm 2.9 \%$ of control, $n=7, P<0.01$; Fig. 5A). Moreover, TXA induced an inward current $(>5 \mathrm{pA})$ in all recording neurons $(n=7$; Fig. $5 \mathrm{~A})$. The average peak amplitude of the TXA-induced inward current was $6.0 \pm 8.1 \mathrm{pA}$. In contrast, neither the mean mEPSC amplitude (control, $7.5 \pm 1.6$; TXA, $7.5 \pm 1.6 \mathrm{pA}, 100.2 \pm 3.6 \%$ of control; $n=7, P=0.99$; Fig. $5 \mathrm{~B}$ ) nor frequency (control, $7.2 \pm 3.0$; TXA, $7.2 \pm 3.0 \mathrm{~Hz}, 100.5 \pm 1.9 \%$ of control; $n=7, P=0.98$ ) was affected in the presence of TXA with mEPSCs isolated by adding TTX. Furthermore, the TXA-induced inward current was suppressed by adding TTX in all recording neurons $(n=7$; Fig. 5B). These results suggest that TXA does not affect the presynaptic terminals of excitatory neurons, because TXA has no effect on the frequency of mEPSCs. In contrast, our results instead suggest that TXA acts on the somata of excitatory neurons, and by reducing inhibition facilitates glutamate release, which causes neuronal excitation, because TXA increases inward current and the frequency of sEPSCs but does not affect sEPSC/mEPSC amplitude.

TXA increases the integrated area of polysynaptic EPSCs evoked by dorsal root stimulation. Primary afferent nerve fibers, such as $\mathrm{A} \delta$ and $\mathrm{C}$ fibers, terminate in the superficial layers of the spinal cord, particularly on SG neurons, and modulate pain information ${ }^{34,35}$. Therefore, we examined whether TXA acts on primary afferent terminals. Monosynaptic EPSCs evoked at A $\delta$ fiber stimulation intensity can be mediated by A $\delta$ fibers; however, polysynaptic EPSCs evoked at A $\delta$ fiber stimulation intensity can be mediated by A $\beta$ and A $\delta$ fibers. Similarly, monosynaptic EPSCs evoked at C fiber stimulation intensity can be mediated by $\mathrm{C}$ fibers; however, polysynaptic EPSCs evoked at C fiber stimulation intensity can be mediated by $\mathrm{A} \beta, \mathrm{A} \delta$, and $\mathrm{C}$ fibers.

The amplitude of monosynaptic EPSCs evoked by A $\delta$ fiber stimulation was not affected by TXA application (control, $274.5 \pm 179.7$; TXA, $271.0 \pm 183.3$ pA, $97.7 \pm 5.7 \%$ of control; $n=7, P=0.97$; Fig. 5 C). In contrast, TXA significantly increased the integrated area of polysynaptic EPSCs to $144.7 \pm 18.8 \%$ of control $(n=7, P<0.01)$. Similarly, the amplitude of monosynaptic EPSCs evoked by C fiber stimulation was not affected by TXA application (control, $355.0 \pm 184.6$; TXA, $347.0 \pm 183.1 \mathrm{pA}, 97.3 \pm 4.0 \%$ of control; $n=7, P=0.94$; Fig. 5D), but the integrated area of polysynaptic EPSCs was significantly increased to $140.8 \pm 25.0 \%$ of control $(n=7, P<0.01)$.

These data indicated that TXA does not affect the primary afferent terminals of $A \delta$ and $C$ fibers, because it did not change the amplitude of monosynaptic $A \delta$ or C fiber-mediated EPSCs. On the other hand, since TXA increased the integrated area of polysynaptic EPSCs evoked at A $\delta$ or C fiber stimulation 
A

B

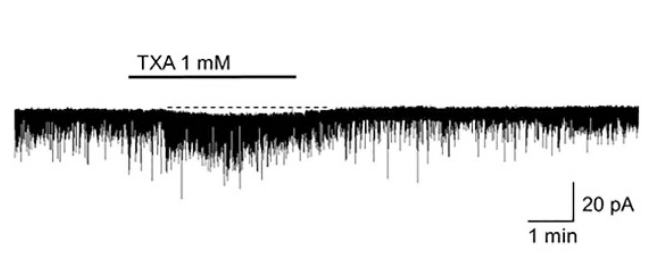

$\operatorname{TTX} 1 \mu \mathrm{M}$
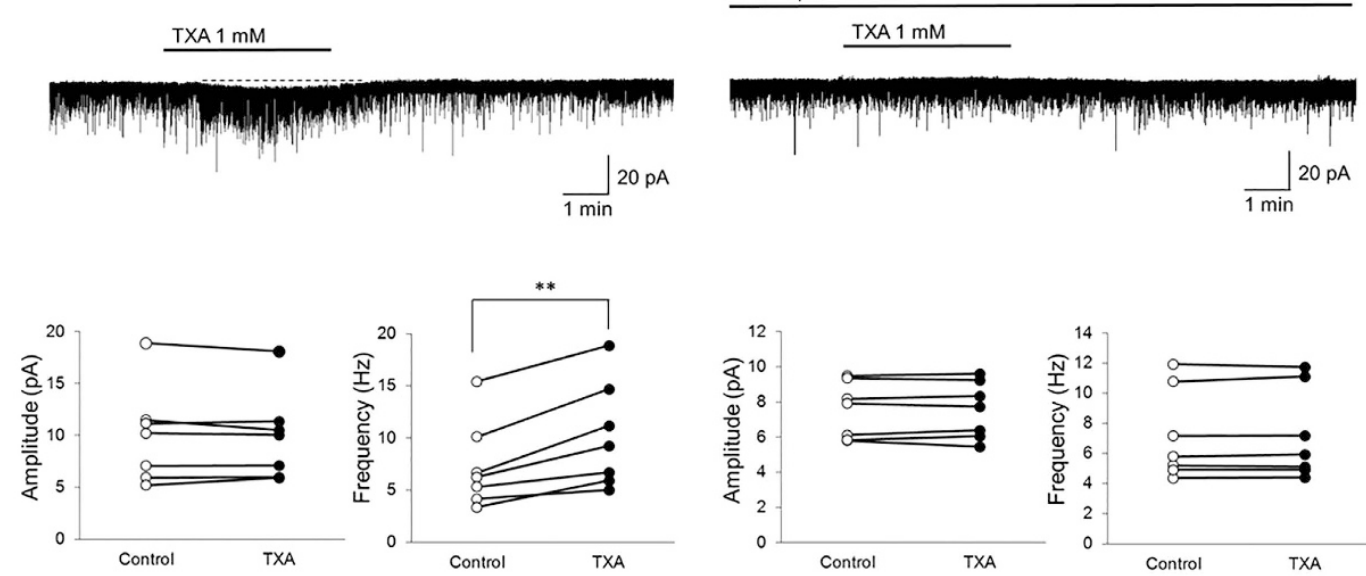

C

D
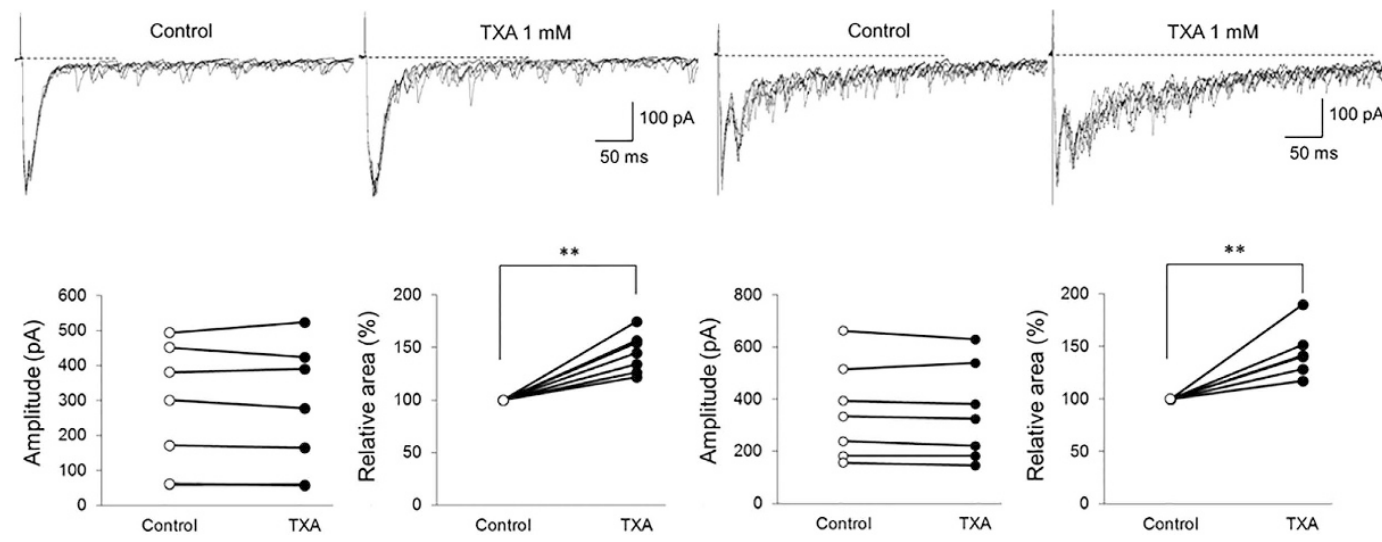

Figure 5. Tranexamic acid (TXA) facilitates excitatory glutamatergic transmission. (A) TXA (1 mM, $2 \mathrm{~min}$ ) has no effect on the amplitude of spontaneous excitatory postsynaptic currents (sEPSCs). In contrast, TXA significantly increases sEPSC frequency $(n=7)$. Moreover, TXA induced inward currents $(>5 \mathrm{pA})$ in all recorded neurons $(n=7)$. (B) TXA $(1 \mathrm{mM}, 2 \mathrm{~min})$ has no effect on mEPSC amplitude or frequency $(n=7)$. (C) TXA has no effect on the amplitude of A $\delta$ fiber-evoked monosynaptic EPSCs. In contrast, TXA significantly increases the integrated area of A $\delta$ fiber-evoked polysynaptic EPSCs $(n=7)$. (D) TXA has no effect on the amplitude of C fiber-evoked monosynaptic EPSCs. In contrast, TXA significantly increases the integrated area of $\mathrm{C}$ fiber-evoked polysynaptic EPSCs $(n=7)$. Holding potential $=-70 \mathrm{mV}$ for all recordings. ${ }^{*} P<0.01$ by paired $t$-test.

intensity, we concluded that TXA acts on excitatory interneurons and facilitates excitatory transmission from primary afferents indirectly.

TXA enhances ERK activation. To obtain spatial information on neuronal excitation in the spinal dorsal horn, we investigated the effect of TXA on neuronal pERK expression, which is indicative of pain. There were very few pERK-positive neurons in the superficial dorsal horn of control spinal cord slices when perfused with standard Krebs solution. However, following application of TXA to the perfusate for $10 \mathrm{~min}$, the number of pERK-positive neurons significantly increased from $5.2 \pm 1.4$ to $13.1 \pm 2.5(n=7$, $P<0.01$, Fig. 6). These results suggested that TXA enhances ERK activation.

\section{Discussion}

We demonstrated that intrathecally or intraperitoneally administered TXA produces behaviors indicative of spontaneous pain and mechanical allodynia in rat in a concentration-dependent manner. To clarify the mechanism underlying these pain behaviors, we investigated the action of TXA on synaptic transmission in spinal dorsal horn neurons. We found that TXA alters excitatory and inhibitory activity at the spinal cord level, which could ultimately result in the experience of pain. 

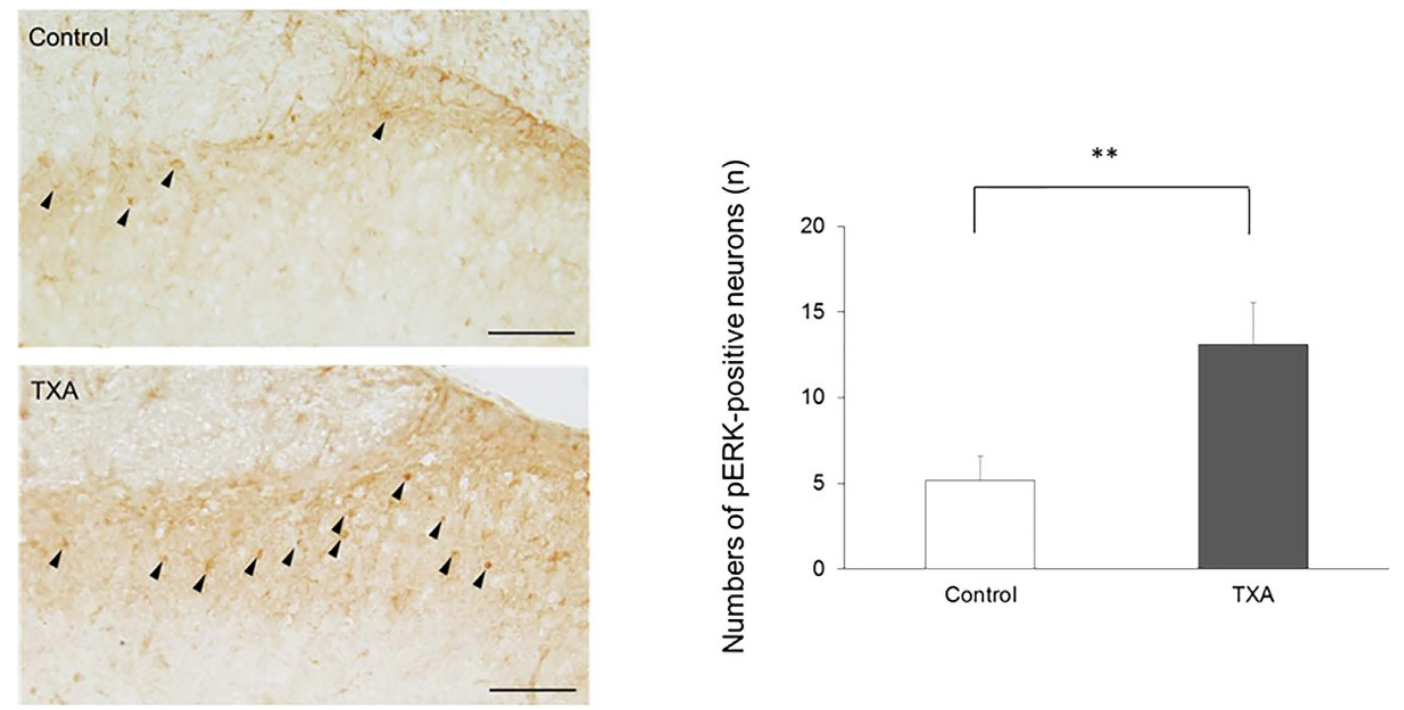

Figure 6. Tranexamic acid (TXA) enhances ERK activation in the superficial dorsal horn of the spinal cord. Under Krebs solution, few neurons are positive for pERK, an indicator of nociceptive stimulation, in slices of the superficial dorsal horn of the spinal cord $(n=7)$. In contrast, TXA $(1 \mathrm{mM}, 10 \mathrm{~min})$ significantly increases the number of pERK-positive neurons $(n=7)$. ERK activation was quantified by counting the number of pERK-labeled neurons in the superficial dorsal horn in control and TXA groups. Filled arrowheads indicate pERK-positive neurons. $\mathrm{Bar}=50 \mu \mathrm{m}$. The data are given as mean $\pm \mathrm{SD}$. ${ }^{\star \star} P<0.01$ by unpaired $t$-test.

TXA inhibits $\mathrm{GABA}_{\mathrm{A}}$ and glycine receptors in spinal dorsal horn neurons. GABA and glycine are major inhibitory neurotransmitters in the central nervous system, and antagonism at their receptors causes seizure ${ }^{36-38}$. Therefore, TXA-associated seizure is presently attributed to inhibition of GABA and glycine receptors in the brain ${ }^{14-16}$. It is also known that GABA and glycine receptors are particularly abundant in the spinal dorsal horn and important for sensory processing ${ }^{17-20}$. Furthermore, spinal $\mathrm{GABA}_{\mathrm{A}}$ and glycine receptors are co-localized on postsynaptic neurons, and these two neurotransmitters work together in sensory modulation ${ }^{20,39}$. Therefore, inhibition of spinal $\mathrm{GABA}_{\mathrm{A}}$ and glycine receptors by TXA could dysregulate pain processing. In rodents, intrathecal administration of $\mathrm{GABA}_{\mathrm{A}}$ or glycine receptor antagonists induces spontaneous pain-like biting and escape behaviors in response to light tactile stimulation ${ }^{23,24,40,41}$. Loss of GABAergic and glycinergic function may also manifest as allodynia and hyperalgesia in patients suffering from neuropathic pain. In this study, we demonstrated that TXA produces spontaneous and evoked pain in a concentration-dependent manner. We also demonstrated that TXA acts as a $\mathrm{GABA}_{\mathrm{A}}$ and glycine receptor antagonist, as TXA decreased GABAergic and glycinergic mIPSC amplitude without affecting frequency. Moreover, TXA decreased the amplitudes and integrated areas of currents elicited by exogenous GABA or glycine application. Thus, it is plausible that the observed TXA-associated pain resulted from $\mathrm{GABA}_{\mathrm{A}}$ and glycine receptor inhibition on spinal dorsal horn neurons.

Our findings also indicated that TXA enhances somatic excitability in SG neurons, presumably through direct inhibition of GABA and glycine receptors, as TXA significantly increased the number of action potentials induced in SG neurons by a standard depolarizing pulse. Taken together, our results suggest that TXA facilitates spinal dorsal horn neurons by inhibiting GABA and glycine receptors, resulting in pain of spinal cord origin.

TXA facilitates excitatory transmission. Since TXA was found to modulate inhibitory transmission in spinal dorsal horn neurons, we next investigated whether TXA also affects excitatory transmission. TXA increased the frequency of sEPSC with inward current, but not that of mEPSC, without affecting amplitude, suggesting that TXA facilitates glutamatergic transmission by acting on excitatory SG interneurons. Primary afferent $\mathrm{A} \delta$ or $\mathrm{C}$ fibers reportedly modulate pain information by controlling excitatory and inhibitory interneuron activity ${ }^{34,35}$. As $\mathrm{GABA}_{\mathrm{A}}$ and glycine receptors are thought to reside on these primary afferent terminals ${ }^{18,42}$, we investigated whether TXA acts on primary afferent terminals to modulate excitatory transmission. However, our results indicated that presynaptic inhibition of primary afferent terminals by TXA is not prominent, at least not in the fine afferent fibers of the superficial dorsal horn, because TXA did not affect the amplitude of the monosynaptic EPSCs evoked by stimulation of these fibers. The reason for the difference in results between previous studies and our study was most likely that presynaptic inhibition of primary afferent terminals is exerted exclusively on the large, myelinated $A \alpha / \beta$ fibers in deep dorsal horn ${ }^{43,44}$. Indeed, one study reported that neither $\mathrm{GABA}_{\mathrm{A}}$ 


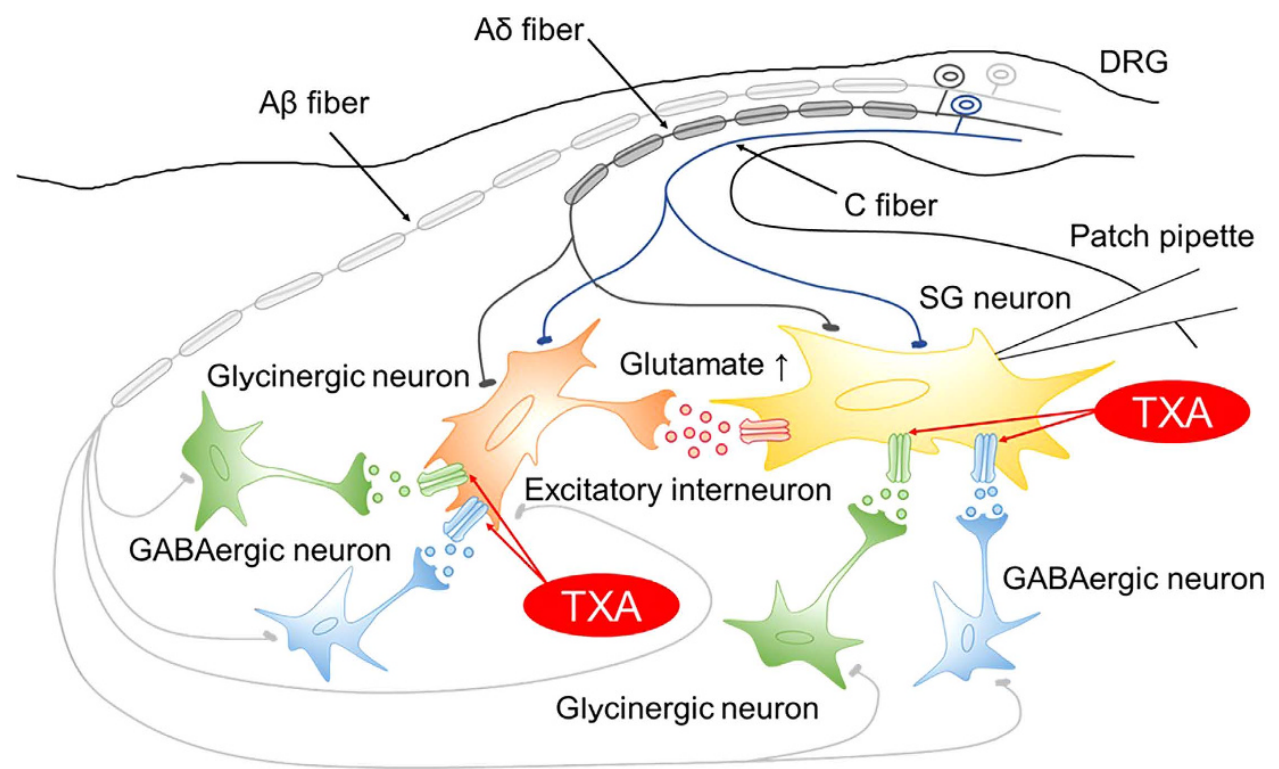

Figure 7. Model of the spinal dorsal horn circuit underlying the mechanism of tranexamic acid (TXA)produced pain. TXA directly inhibits GABA and glycine receptors located on postsynaptic sites of the recorded SG neurons. TXA also inhibits $\mathrm{GABA}_{\mathrm{A}}$ and glycine receptors located on postsynaptic sites on excitatory interneurons. This leads to increased glutamate release from the excitatory interneurons to the recorded SG neurons located postsynaptically, resulting in increased spontaneous activity. SG, substantia gelatinosa; DRG, dorsal root ganglion.

nor glycine receptor agonist/antagonists affect monosynaptic EPSC amplitude in SG neurons ${ }^{33}$. In contrast, our findings suggest that TXA facilitates polysynaptic excitatory transmission because it increased the integrated area of polysynaptic EPSCs evoked by primary afferent stimulation. The abovementioned previous study reported that blockade of GABAergic and glycinergic inhibition facilitated polysynaptic excitatory synaptic transmission in SG neurons ${ }^{33}$. Our findings together with previous reports indicate that TXA enhances the excitability of excitatory interneurons via blockade of GABAergic and glycinergic postsynaptic inhibition, which facilitates excitatory transmission to the SG neurons indirectly.

Given this, we propose the following model circuit for the underlying mechanism of TXA in the spinal dorsal horn (Fig. 7). TXA directly inhibits $\mathrm{GABA}_{\mathrm{A}}$ and glycine receptors located on postsynaptic sites of the recorded SG neurons, resulting in increased neuronal excitability. In addition, TXA inhibits $\mathrm{GABA}_{\mathrm{A}}$ and glycine receptors postsynaptically located on the excitatory interneurons, thus inducing excitability. Consequently, TXA leads to increased glutamate release from presynaptic excitatory interneurons to SG neurons. We propose that these mechanisms could produce pain.

TXA enhances ERK activation, a marker of nociception. To confirm behavioral and electrophysiological evidence that TXA produces pain, we investigated the effect of TXA using immunostaining and demonstrated that TXA enhances ERK activation, a cellular marker of pain processing. ERK is the most intensively studied member of the family of mitogen-activated protein kinases ${ }^{45}$. ERK phosphorylation results from pain, especially in the superficial dorsal horn, and is implicated in the development of central sensitization ${ }^{46,47}$. We demonstrated that TXA increases pERK-positive neurons in the spinal cord, which is consistent with our behavioral data. These results suggested that TXA significantly excites a considerable number of dorsal horn neurons.

TXA levels are within a clinically relevant range. The $1 \mathrm{mM}$ concentration of TXA used in this study was chosen to imitate the effect of the clinical dose of TXA in cerebrospinal fluid. TXA reduces blood loss and transfusion requirements perioperatively at high doses of up to $100 \mathrm{mg} / \mathrm{kg}^{48-51}$. Following administration of $100 \mathrm{mg} / \mathrm{kg}$ TXA, plasma levels exceed $4 \mathrm{mM}^{52}$, resulting in an estimated cerebrospinal fluid TXA concentration of $0.62-1.24 \mathrm{mM}^{12,53,54}$. One previous study showed that TXA has an $\mathrm{IC}_{50}$ value of $7.1 \pm 3.1 \mathrm{mM}$ for recombinant $\mathrm{GABA}_{\mathrm{A}}$ receptors in human embryonic kidney cells ${ }^{14}$, while another study reported $\mathrm{IC}_{50}$ values for TXA against $\mathrm{GABA}_{\mathrm{A}}$ receptors of $0.76-0.84 \mathrm{mM}$ in the murine amygdala ${ }^{15}$. The $\mathrm{IC}_{50}$ values for TXA against glycine receptors were $1.1-1.4 \mathrm{mM}$ in primary cultures of embryonic murine cortical neurons ${ }^{16}$. Given that only $3 \%$ of TXA is bound to protein ${ }^{55}$, the concentration of TXA $(1 \mathrm{mM})$ used in our study is thought to be within a clinically relevant range, and our study suggested that TXA acts directly on spinal neurons. 
The $1 \mathrm{mM}$ concentration of TXA was used in electrophysiological and immunohistochemical experiments because of clinical dose of TXA in cerebrospinal fluid according to the previous reports. However, $1 \mathrm{mM}$ TXA intrathecally administered produced behaviors indicative of very severe spontaneous pain, which could not perform the assessment of behavioral response with von Frey filaments. Therefore, the concentration of TXA intrathecally administered is lower than that used in electrophysiological and immunohistochemical experiments. These results suggest that there is a possibility that TXA produces pain even with lower concentration of $1 \mathrm{mM}$.

In conclusion, we have demonstrated that TXA produces pain by inhibiting $\mathrm{GABA}_{\mathrm{A}}$ and glycine receptors on spinal dorsal horn neurons at clinically relevant concentrations. Collectively, our data describe an underlying mechanism by which TXA can produce pain, and may contribute to the clinical management of TXA-associated pain.

\section{Materials and Methods}

Animals. Male Wistar rats (200-250 g) were used in all experiments. Animals were housed under a 12-h light/dark cycle with ad libitum access to food and water.

Implantation of intrathecal catheter. For intrathecal drug administration, rats were implanted with a polyethylene PE-10 catheter, as previously described, with some modification ${ }^{56}$. Rats were anesthetized with $2-3 \%$ isoflurane, and a PE-10 polyethylene catheter was inserted rostrally into the lumbar enlargement through a mini-laminectomy at the L5 vertebra. The animals were allowed to recover for 3-6 days before experiments. Only animals without evidence of neurological dysfunction after catheter insertion were used for these studies.

Assessment of behavioral response. Rats were acclimated to the experimental room for at least $30 \mathrm{~min}$ before injection of TXA. In the intrathecal group, TXA dissolved in normal saline was administered intrathecally through a catheter in $10-\mu \mathrm{L}$ volume (from 0.001 to $0.1 \mathrm{pmol}$ ), followed by an injection of $10 \mu \mathrm{L}$ of saline to flush the catheter. In the intraperitoneal group, TXA dissolved in normal saline was administered intraperitoneally with a 26-gauge needle in a volume of $1 \mathrm{~mL}$ (from 10 to $100 \mu \mathrm{mol}$ ).

Licking/biting behaviors were counted as a measure of spontaneous pain responses. Moreover, we investigated possible TXA-induced sensitivity to mechanical stimulation to assess evoked pain. The force threshold for paw withdrawal in response to probing with a series of calibrated von Frey filaments was therefore determined. Each filament was applied perpendicularly to the plantar surface of the paw of rats held in wire-mesh cages ${ }^{57}$. The withdrawal threshold was defined as the lowest force that evoked a clear withdrawal response at least twice in 10 applications, and was observed every $10 \mathrm{~min}$ for $60 \mathrm{~min}$, beginning at TXA administration.

Preparation of spinal cord slices. Rats were anesthetized with urethane $(1.5 \mathrm{~g} / \mathrm{kg}$, intraperitoneal). A dorsal laminectomy was performed, and the lumbosacral segment of the spinal cord was removed. Rats were then euthanized immediately by exsanguination. The isolated spinal cords were placed in pre-oxygenated ice-cold Krebs solution. After severing all ventral and dorsal roots, except for the L4 dorsal root, the arachnoid membrane was removed. Each spinal cord was mounted on the metal stage of a microslicer (Linear Slicer PRO 7; Dosaka, Kyoto, Japan) and cut into $650-\mu \mathrm{m}$ transverse slices with the L4 dorsal root attached. The slices were transferred to a recording chamber and perfused continuously with Krebs solution $(10-15 \mathrm{~mL} / \mathrm{min})$ equilibrated with a $95 \% \mathrm{O}_{2} / 5 \% \mathrm{CO}_{2}$ gas mixture at $36^{\circ} \mathrm{C}$. The Krebs solution contained the following (in $\mathrm{mM}$ ): $\mathrm{NaCl} 117, \mathrm{KCl} 3.6, \mathrm{CaCl}_{2}$ 2.5, $\mathrm{MgCl}_{2} 1.2, \mathrm{NaH}_{2} \mathrm{PO}_{4} 1.2$, $\mathrm{NaHCO}_{3} 25$, and D-glucose 11.5.

Patch clamp recording from dorsal horn neurons. Under a dissecting microscope with transmission illumination, lamina II of the dorsal horn was discernible as a relatively translucent band across the dorsal horn. Whole-cell patch-clamp recording of substantia gelatinosa (SG) neurons was conducted in voltage-clamp mode. After establishing the whole-cell configuration, voltage-clamped neurons were held at $-70 \mathrm{mV}$ for recording excitatory postsynaptic currents (EPSCs) and at $0 \mathrm{mV}$ for recording inhibitory postsynaptic currents (IPSCs). The resistance of the patch pipette was 5-10 M $\Omega$. The patch pipette solution contained the following (in mM): $\mathrm{Cs}_{2} \mathrm{SO}_{4} 110, \mathrm{CaCl}_{2} 0.5, \mathrm{MgCl}_{2}$ 2, EGTA 5, HEPES 5, tetraethylammonium 5, and ATP-Mg 5. Signals were amplified using an Axopatch 200B amplifier (Molecular Devices, Union City, CA) and were filtered at $2 \mathrm{kHz}$ and digitized at $5 \mathrm{kHz}$. Data were collected and analyzed using the pCLAMP 10.4 software suite (Molecular Devices).

Dorsal root stimulation. The L4 dorsal root was stimulated using a suction electrode. Stimulation was performed at $100 \mu \mathrm{A}$ for $0.05 \mathrm{~ms}$ for A $\delta$ fibers, and at $1000 \mu \mathrm{A}$ for $0.5 \mathrm{~ms}$ for $\mathrm{C}$ fibers. A $\delta$ fiber-evoked EPSCs were judged monosynaptic based on both their short and constant latencies and the absence of failures with repetitive stimulation at $20 \mathrm{~Hz}^{35}$. C fiber-evoked EPSCs were judged monosynaptic based on an absence of failures with low-frequency $(1 \mathrm{~Hz})$ repetitive stimulation. In contrast, polysynaptic EPSCs were recognized by their unreliable, variable latencies under such stimulation protocols. 
Action potential discharge activity. The effect of TXA $(1 \mathrm{mM})$ on action potential discharge activity was examined in current-clamp mode using patch pipettes filled with potassium gluconate instead of cesium sulfate. The patch pipette solution contained the following (in $\mathrm{mM}$ ): potassium gluconate 135, $\mathrm{KCl} 5, \mathrm{CaCl}_{2} 0.5, \mathrm{MgCl}_{2}$ 2, EGTA 5, and Mg-ATP 5. In response to a depolarizing current injection of $100 \mathrm{pA}$ for $1000 \mathrm{~ms}$, SG neurons exhibited a train of action potentials, and we investigated the effect of TXA on the number of action potential discharges.

Immunohistochemistry. To measure the effect of TXA on spinal dorsal horn with phosphorylated extracellular signal-regulated kinase (pERK), spinal cord slices were perfused with Krebs solution for at least $3 \mathrm{~h}$ before TXA application, after which TXA $(1 \mathrm{mM})$ was applied in the perfusate for $10 \mathrm{~min}$. After drug treatment, the slices were fixed in $4 \%$ paraformaldehyde for $60 \mathrm{~min}$, equilibrated with sucrose overnight, cut on a cryostat at a thickness of $16 \mu \mathrm{m}$, and mounted on slides. Sections were incubated with rabbit anti-pERK1/2 antibody (Cell Signaling Technology, Danvers, MA; 1:1,000) for 2 days at $4{ }^{\circ} \mathrm{C}$. The sections were then incubated with biotinylated anti-rabbit secondary antibody (Vector Laboratories, Burlingame, CA; 1:400) for $4 \mathrm{~h}$ at room temperature. Sections were then processed with a Vectastain ABC system kit (Vector Laboratories) following the manufacturer's instructions. To determine the mean number of pERK-positive neurons in the superficial laminae (I-II), at least five nonadjacent sections were randomly selected, and cells were counted under a microscope-digital camera system (Nikon, Tokyo, Japan).

Drug application. The drugs used in this study were TXA, bicuculline, strychnine, GABA, glycine (all from Sigma-Aldrich, St. Louis, MO) and tetrodotoxin (TTX; from Wako, Osaka, Japan). Bicuculline was first dissolved in DMSO at a 1,000 times the final concentration for storage, and the other drugs were first dissolved in distilled water at a 1,000 times the final concentrations for storage. These stock solutions were diluted to the final concentration with Krebs solution immediately before use.

Study approval. All animal experiments were conducted in accordance with international guidelines on the ethical use of animals, and all efforts were made to minimize the amount of pain or discomfort experienced by the animals. Animal housing and surgical procedures were approved by the Institutional Animal Care and Use Committee of Niigata University Graduate School of Medical and Dental Science (Approval No. 342-7).

Statistical Analysis. Data are expressed as mean \pm SD. Statistical significance was defined as $P<0.05$ by a Student's paired or unpaired $t$-test, one or two-way ANOVA followed by a Bonferroni post hoc test for multiple comparisons. The StatView program 5 (SAS Institute, Cary, NC, USA) was used for statistical analysis.

\section{References}

1. Andersson, L., Nilsoon, I. M., Colleen, S., Granstrand, B. \& Melander, B. Role of urokinase and tissue activator in sustaining bleeding and the management thereof with EACA and AMCA. Ann. NY. Acad. Sci. 146, 642-658 (1968).

2. Dunn, C. J. \& Goa, K. L. Tranexamic acid: a review of its use in surgery and other indications. Drugs 57, 1005-1032 (1999).

3. Hoylaerts, M., Lijnen, H. R. \& Collen, D. Studies on the mechanism of the antifibrinolytic action of tranexamic acid. Biochim. Biophys. Acta. 673, 75-85 (1981).

4. Iwamoto, M. Plasminogen-plasmin system IX. Specific binding of tranexamic acid to plasmin. Thromb. Diath. Haemorrh. 33, 573-585 (1975).

5. Thorsen, S. Differences in the binding to fibrin of native plasminogen and plasminogen modified by proteolytic degradation. Influence of omega-aminocarboxylic acids. Biochim. Biophys. Acta. 393, 55-65 (1975).

6. Armellin, G. et al. Tranexamic acid in aortic valve replacement. J. Cardiothorac. Vasc. Anesth. 15, 331-335 (2001).

7. Elgafy, H., Bransford, R. J., McGuire, R. A., Dettori, J. R. \& Fischer, D. Blood loss in major spine surgery: are there effective measures to decrease massive hemorrhage in major spine fusion surgery? Spine 35, S47-56 (2010).

8. Giordano, R. et al. Tranexamic acid therapy in pediatric cardiac surgery: a single-center study. Annals. Thorac. Surg. 94, 1302-1306 (2012).

9. Panteli, M., Papakostidis, C., Dahabreh, Z., \& Giannoudis, P. V. Topical tranexamic acid in total knee replacement: a systematic review and meta-analysis. Knee 20, 300-309 (2013).

10. Taghaddomi, R. J., Mirzaee, A., Attar, A. S., \& Shirdel, A. Tranexamic acid reduces blood loss in off-pump coronary artery bypass surgery. J. Cardiothorac. Vasc. Anesth. 23, 312-315 (2009).

11. Kalavrouziotis, D., Voisine, P., Mohammadi, S., Dionne, S., \& Dagenais, F. High-dose tranexamic acid is an independent predictor of early seizure after cardiopulmonary bypass. Ann. Thorac. Surg. 93, 148-154 (2012).

12. Murkin, J. M. et al. High-dose tranexamic Acid is associated with nonischemic clinical seizures in cardiac surgical patients. Anesth. Analg. 110, 350-353 (2010).

13. Sharma, V. et al. The association between tranexamic acid and convulsive seizures after cardiac surgery: a multivariate analysis in 11529 patients. Anaesthesia 69, 124-130 (2014).

14. Furtmuller, R. et al. Tranexamic acid, a widely used antifibrinolytic agent, causes convulsions by a gamma-aminobutyric acid (A) receptor antagonistic effect. J. Pharmacol. Exp. Ther. 301, 168-173 (2002).

15. Kratzer, S. et al. Tranexamic acid impairs gamma-aminobutyric acid receptor type A-mediated synaptic transmission in the murine amygdala: a potential mechanism for drug-induced seizures? Anesthesiology 120, 639-649 (2014).

16. Lecker, I. et al. Tranexamic acid concentrations associated with human seizures inhibit glycine receptors. J. Clin. Invest. 122, 4654-4666 (2012).

17. Game, C. J. \& Lodge, D. The pharmacology of the inhibition of dorsal horn neurones by impulses in myelinated cutaneous afferents in the cat. Exp. Brain. Res. 23, 75-84 (1975). 
18. Todd, A. J. An electron microscope study of glycine-like immunoreactivity in laminae I-III of the spinal dorsal horn of the rat. Neuroscience 39, 387-394 (1990).

19. Todd, A. J. \& Lochhead, V. GABA-like immunoreactivity in type I glomeruli of rat substantia gelatinosa. Brain Res. 514, 171-174 (1990).

20. Todd, A. J., Watt, C., Spike, R. C. \& Sieghart, W. Colocalization of GABA, glycine, and their receptors at synapses in the rat spinal cord. J. Neurosci. 16, 974-982 (1996).

21. Ishikawa, T., Marsala, M., Sakabe, T. \& Yaksh, T. L. Characterization of spinal amino acid release and touch-evoked allodynia produced by spinal glycine or GABA (A) receptor antagonist. Neuroscience 95, 781-786 (2000).

22. Loomis, C. W., Khandwala, H., Osmond, G. \& Hefferan, M. P. Coadministration of intrathecal strychnine and bicuculline effects synergistic allodynia in the rat: an isobolographic analysis. J. Pharmacol. Exp. Ther. 296, 756-761 (2001).

23. Onaka, M., Minami, T., Nishihara, I. \& Ito, S. Involvement of glutamate receptors in strychnine- and bicuculline-induced allodynia in conscious mice. Anesthesiology 84, 1215-1222 (1996).

24. Yaksh, T. L. Behavioral and autonomic correlates of the tactile evoked allodynia produced by spinal glycine inhibition: effects of modulatory receptor systems and excitatory amino acid antagonists. Pain 37, 111-123 (1989).

25. Butala, B. P., Shah, V. R., Bhosale, G. P. \& Shah, R. B. Medication error: Subarachnoid injection of tranexamic acid. Indian J. Anaesth. 56, 168-70 (2012).

26. de Leede-van der Maarl, M. G., Hilkens, P. \& Bosch, F. The epileptogenic effect of tranexamic acid. J. Neurol. 246, 843 (1999).

27. Garcha, P. S., Mohan, C. V. \& Sharma, R. M. Death after an inadvertent intrathecal injection of tranexamic acid. Anesth. Analg. 104, 241-242 (2007)

28. Kaabachi, O., Eddhif, M., Rais, K. \& Zaabar, M. A. Inadvertent intrathecal injection of tranexamic acid. Saudi J. Anaesth. 5, 90-92 (2011).

29. Mohseni, K., Jafari, A., Nobahar, M. R. \& Arami, A. Polymyoclonus seizure resulting from accidental injection of tranexamic acid in spinal anesthesia. Anesth. Analg. 108, 1984-1986 (2009).

30. Kassell, N. F., Torner, J. C. \& Adams, H. P. Jr. Antifibrinolytic therapy in the acute period following aneurysmal subarachnoid hemorrhage. Preliminary observations from the Cooperative Aneurysm Study. J. Neurosurg. 61, 225-230 (1984).

31. Remerand, F. et al. Tranexamic acid decreases risk of haematomas but not pain after hip arthroplasty. Orthop. Traumatol. Surg. Res. 99, 667-673 (2013).

32. Lukes, A. S., Freeman, E. W., Van Drie, D., Baker, J. \& Adomako, T. L. Safety of tranexamic acid in women with heavy menstrual bleeding: an open-label extension study. Womens Health (London, England) 7, 591-598 (2011).

33. Baba, H. et al. Removal of GABAergic inhibition facilitates polysynaptic A fiber-mediated excitatory transmission to the superficial spinal dorsal horn. Mol. Cell. Neurosci. 24, 818-830 (2003).

34. Kumazawa, T. \& Perl, E. R. Excitation of marginal and substantia gelatinosa neurons in the primate spinal cord: indications of their place in dorsal horn functional organization. J. Comp. Neurol. 177, 417-34 (1978).

35. Yoshimura, M. \& Jessell, T. M. Primary afferent-evoked synaptic responses and slow potential generation in rat substantia gelatinosa neurons in vitro. J. Neurophysiol. 62, 96-108 (1989).

36. Bormann, J. Electrophysiology of GABAA and GABAB receptor subtypes. Trends. Neurosci. 11, 112-116 (1988)

37. Bormann, J. Patch-clamp analysis of GABA- and glycine-gated chloride channels. Adv. Biochem. Psychopharmacol. 45, 47-60 (1988).

38. Bormann, J., Hamill, O. P. \& Sakmann, B. Mechanism of anion permeation through channels gated by glycine and gammaaminobutyric acid in mouse cultured spinal neurones. J. Physiol. 385, 243-286 (1987).

39. Mitchell, K., Spike, R. C. \& Todd, A. J. An immunocytochemical study of glycine receptor and GABA in laminae I-III of rat spinal dorsal horn. J. Neurosci. 13, 2371-2381 (1993).

40. Milne, B., Duggan, S., Jhamandas, K. \& Loomis, C. Innocuous hair deflection evokes a nociceptive-like activation of catechol oxidation in the rat locus coeruleus following intrathecal strychnine: a biochemical index of allodynia using in vivo voltammetry. Brain Res. 718, 198-202 (1996).

41. Sivilotti, L. \& Woolf, C. J. The contribution of GABAA and glycine receptors to central sensitization: disinhibition and touchevoked allodynia in the spinal cord. J. Neurophysiol. 72, 169-179 (1994).

42. MacDermott, A. B., Role, L. W. \& Siegelbaum, S. A. Presynaptic ionotropic receptors and the control of transmitter release. Annu Rev Neurosci 22, 443-485 (1999).

43. Rudomin, P. Primary afferent depolarization produced in Adelta and C fibres by glutamate spillover? New ways to look at old things. J. Physiol. 528 Pt 1, 1 (2000).

44. Rudomin, P. \& Schmidt, R. F. Presynaptic inhibition in the vertebrate spinal cord revisited. Exp. Brain Res. 129, 1-37 (1999).

45. Seger, R. \& Krebs, E. G. The MAPK signaling cascade. FASEB J. 9, 726-735 (1995).

46. Ji, R. R., Baba, H., Brenner, G. J. \& Woolf, C. J. Nociceptive-specific activation of ERK in spinal neurons contributes to pain hypersensitivity. Nat. Neurosci. 2, 1114-1119 (1999).

47. Kawasaki, Y. et al. Ionotropic and metabotropic receptors, protein kinase A, protein kinase C, and Src contribute to C-fiberinduced ERK activation and cAMP response element-binding protein phosphorylation in dorsal horn neurons, leading to central sensitization. J. Neurosci. 24, 8310-8321 (2004).

48. Karski, J. et al. Tranexamic acid and early saphenous vein graft patency in conventional coronary artery bypass graft surgery: a prospective randomized controlled clinical trial. J. Thorac. Cardiovasc. Surg. 130, 309-314 (2005).

49. Karski, J. M. et al. Prevention of bleeding after cardiopulmonary bypass with high-dose tranexamic acid. Double-blind, randomized clinical trial. J. Thorac. Cardiovasc. Surg. 110, 835-42 (1995).

50. Karski, J. M. et al. The effect of three different doses of tranexamic acid on blood loss after cardiac surgery with mild systemic hypothermia (32 degrees C). J. Cardiothorac. Vasc. Anesth. 12, 642-646 (1995).

51. Fergusson, D. A. et al. A comparison of aprotinin and lysine analogues in high-risk cardiac surgery. N. Engl. J. Med. 358, 2319-2331 (2008).

52. Dowd, N. P. et al. Pharmacokinetics of tranexamic acid during cardiopulmonary bypass. Anesthesiology 97, 390-399 (2002).

53. Fodstad, H., Pilbrant, A., Schannong, M. \& Stromberg, S. Determination of tranexamic acid (AMCA) and fibrin/fibrinogen degradation products in cerebrospinal fluid after aneurysmal subarachnoid haemorrhage. Acta. Neurochir. 58, 1-13 (1981).

54. Yamaura, A., Nakamura, T., Makino, H. \& Hagihara, Y. Cerebral complication of antifibrinolytic therapy in the treatment of ruptured intracranial aneurysm. Animal experiment and a review of literature. Eur. Neurol. 19, 77-84 (1980).

55. McCormack, P. L. Tranexamic acid: a review of its use in the treatment of hyperfibrinolysis. Drugs 72, 585-617 (2012).

56. Pogatzki, E. M., Zahn, P. K. \& Brennan, T. J. Lumbar catheterization of the subarachnoid space with a 32-gauge polyurethane catheter in the rat. Eur. J. Pain 4, 111-113 (2000).

57. Chaplan, S. R., Bach, F. W., Pogrel, J. W., Chung, J. M. \& Yaksh, T. L. Quantitative assessment of tactile allodynia in the rat paw. J. Neurosci. Methods 53, 55-63 (1994). 


\section{Acknowledgements}

The authors would like to thank Hiroaki Tsukano and Masao Horie for their technical assistance. This research was supported by a Grant-in-Aid for Exploratory Research (Grant Number 25670668) from the Ministry of Education, Culture, Sports, Science, and Technology of Japan, Tokyo, Japan.

\section{Author Contributions}

N.O., Y.K. and H.B. designed the experiments; N.O., M.S. and M.O. conducted experiments and analyzed the data; N.O. and T.K. wrote the manuscript. All authors reviewed the manuscript.

\section{Additional Information}

Competing financial interests: The authors declare no competing financial interests.

How to cite this article: Ohashi, N. et al. Tranexamic acid evokes pain by modulating neuronal excitability in the spinal dorsal horn. Sci. Rep. 5, 13458; doi: 10.1038/srep13458 (2015).

(c) (i) This work is licensed under a Creative Commons Attribution 4.0 International License. The images or other third party material in this article are included in the article's Creative Commons license, unless indicated otherwise in the credit line; if the material is not included under the Creative Commons license, users will need to obtain permission from the license holder to reproduce the material. To view a copy of this license, visit http://creativecommons.org/licenses/by/4.0/ 